\title{
O MOVIMENTO DO PEDESTRE NO CRUZAMENTO DA AVENIDA PAULISTA COM A RUA DA CONSOLAÇÃO. PASSAGEM OU PERMANÊNCIA?
}

\author{
Isabelle Cristina Maciel de Brito Soares ${ }^{1}$
}

Yara Cristina Labronici Baiardi ${ }^{2}$

\begin{abstract}
RESUMO
Este artigo analisa o movimento de pedestres no entorno do cruzamento de São Paulo: a Rua da Consolação com a Avenida Paulista. Essa região abriga um nó do sistema de transportes, composto pela conexão de duas linhas de metrô e um corredor de ônibus. O problema que se apresenta nessa pesquisa é a falta de um desenho urbano que contemple os sistemas de infraestrutura de transporte articulado com o movimento do pedestre e contexto urbano. É por meio da análise comportamental da observação direta pela metodologia desenvolvida pelo arquiteto dinamarquês Jan Ghel (2013), que será analisado o espaço público e a escala humana para um melhor desenho urbano desse cruzamento. Apresenta-se, aqui, a síntese de uma pesquisa que avalia condições de mobilidade do pedestre nos espaços públicos, por meio de análise das relações entre caminhar, passar e permanecer, assim como a interdependência entre o uso do solo, as condições físicas do espaço público e como acontece o movimento do pedestre no meio urbano.
\end{abstract}

Palavras-chave: Pedestre, mobilidade urbana, espaço público.

\section{THE PEDESTRIAN CROSSING IN MOTION PAULISTA AVENUE WITH STREET CONSOLATION. PASS OR STAY?}

\section{ABSTRACT}

This paper assess the situation of pedestrian movement on an important crossing of the City of São Paulo, Street of Consolação and Avenida Paulista. This region comprises a node of urban

\footnotetext{
${ }_{1}^{1}$ Mestranda em Urbanismo na Universidade Presbiteriana Mackenzie. isoaresarquitetura@gmail.com

${ }^{2}$ Mestre em Urbanismo. Doutoranda na Universidade Presbiteriana Mackenzie. yaclba@yahoo.com.br
} 


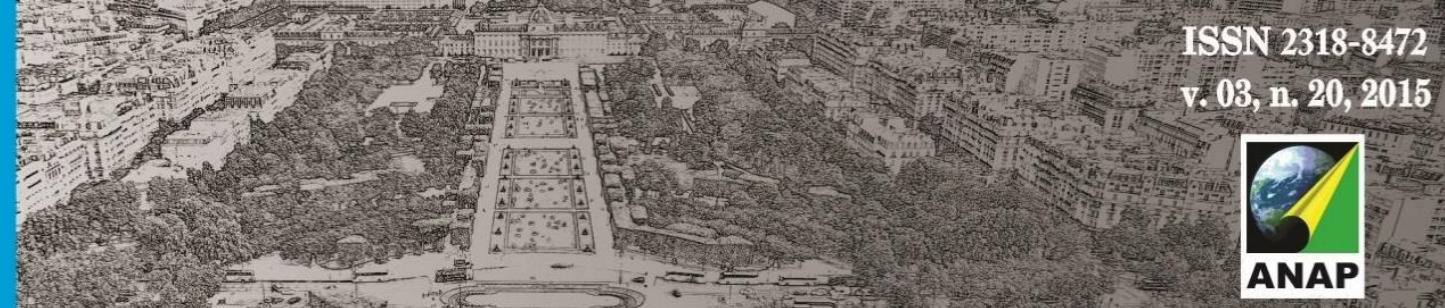

Revista Nacional de

Gerenciamento de Cidades

atividades econômicas e de lazer, modais de ligação com diversas regiões da cidade e que, portanto, atrai inúmeros pedestres.

Quando o assunto é mobilidade, o espaço público adquire um caráter central, visto que a ampliação da mobilidade pedonal, seja ela complementar ao transporte público ou como principal meio de transporte das pessoas, oferece vantagens essenciais à população e à cidade. Nas centralidades urbana e junto aos equipamentos de transportes público, o espaço público, assume, por um lado, a função de ampliar a microacessiblidade dos usuários (Baiardi, 2013).

Utilizando o método da análise do Desenho Urbano, por meio da análise comportamental no meio físico, forma usada por Jan Gehl, o qual desenvolveu um modo que analisa o espaço público levando em conta a escala humana para melhor projetá-lo, apresenta-se, neste artigo, a síntese de uma pesquisa que avalia as condições de mobilidade dos pedestres nas calçadas do encontro destas duas vias, em articulação com os sistemas de transportes públicos existentes.

\section{PEDESTRE E ESPAÇO PÚBLICO: PERMANÊNCIA E PASSAGEM}

Em um contexto de crescimento urbano, as pessoas necessitam se deslocar, por diversos motivos, ao longo de grandes distâncias e para diversos destinos, utilizando uma variedade de meios de transporte e que envolve diferentes velocidades e modos. Os cidadãos demandam cada vez mais qualidade, mais atenção em seus percursos individuais, maior intensidade, urbanidade, velocidade e acesso à grande metrópole, se possível, com tranquilidade e qualidade. A questão das passagens como espaço de transição, torna-se um desafio decisivo para facilitar os acessos aos diferentes equipamentos urbanos, em especial, os sistemas de transporte publico.

Se por um lado a mobilidade se tornou cada vez mais complexa, as redes de transporte, por sua vez, continuam a ser pensadas de maneira isolada. Mesmo assim, o usuário avalia a qualidade de seu deslocamento em termos de eficácia, 


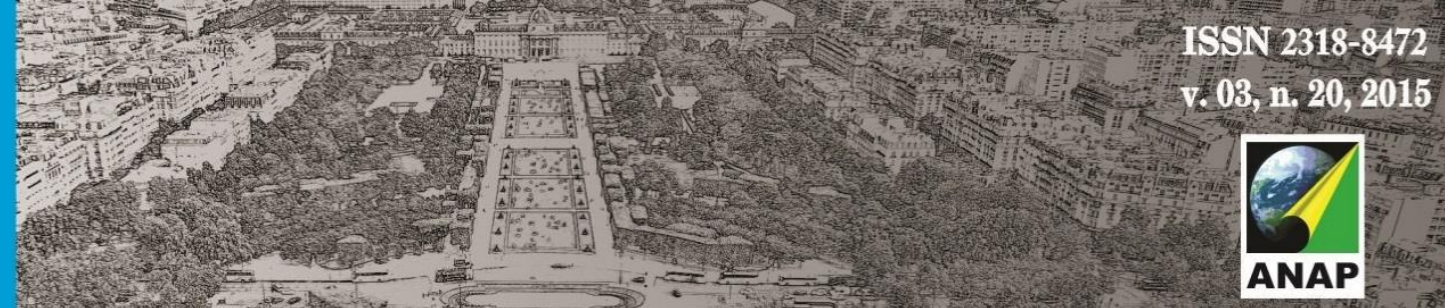

Revista Nacional de

Gerenciamento de Cidades

conforto, segurança e qualidade urbana tomando em conta a totalidade do percurso. As passagens surgem então como o elo que permite passar de uma rede de transporte para outra, com distintos graus de facilidade ou acessibilidade, garantindo, assim, a conclusão exitosa do circuito de mobilidade urbana (IVM-2014).

Smetz (2014) fala da passagem moderna e que a multiplicação dos automóveis exigiu um sistema de circulação eficaz e autônomo, separando fluxos por meio de uma hierarquia da infraestrutura agressiva, infraestruturas rodoviaristas essas que colocam barreiras nos tecidos urbanos. Então, na passagem moderna, cada modal atende sua própria lógica de transporte, concebendo passagens tecnocratas sem a valorização do espaço e do sentido social delas. $\mathrm{Na}$ cidade modernista houve a necessidade de dar espaço ao automóvel, sistema que tirou a prioridade do pedestre no espaço urbano. Smetz (2014) fala da passagem moderna e que a multiplicação dos automóveis exigiu um sistema de circulação eficaz e autônomo. As rodovias penetraram na cidade, assim como os boulevares circulares. Houve também o crescimento periférico e a ligação entre subúrbios. O urbanismo de zoneamento, a monofuncionalidade das grandes infraestruturas (grandes autoestradas, faixas preferenciais, vias férreas, e por que não, os corredores de BRT) contribuíram para criar novos limites, às vezes, intransponíveis. Aquilo que foi concebido originalmente para unir constitui hoje uma separação, um impedimento para a mobilidade dos indivíduos, que frequentemente encontram-se obrigados a inventar passagens informais, e muitas vezes perigosas, para se deslocar.

Porém, na cidade contemporânea, vive-se uma transição do espaço urbano, a rua vem adquirindo um papel central na discussão acerca da urbanidade das cidades, principalmente quando tem uma forte relação com os seus transeuntes, ou seja, a rua, além de espaço de passagem, é também um espaço de permanência, mesmo que não permanente.

As passagens contemporâneas, com uma visão geral das opções comuns de design que pretendem melhorar a monotonia de passagens tecnocráticas existentes, mostra que, se quisermos chegar a verdadeiramente significativas intervenções, 


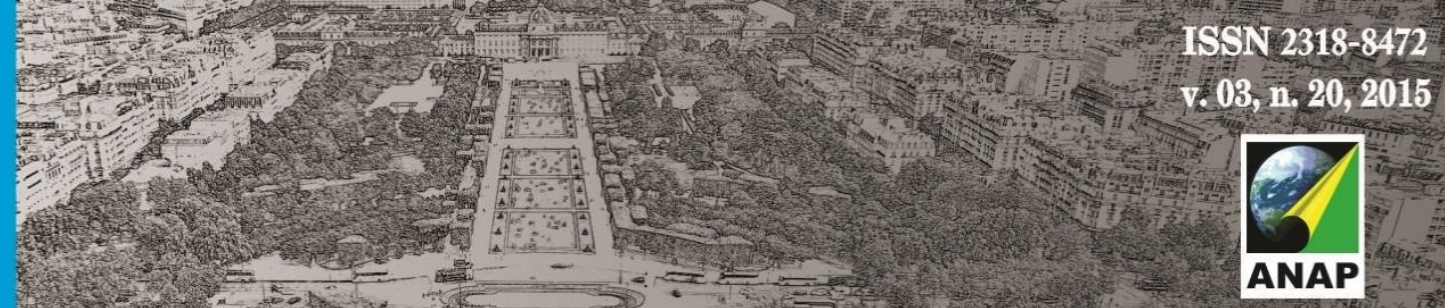

Revista Nacional de

Gerenciamento de Cidades

precisamos superar os recursos de embelezamento meramente formal. Precisamos ir além da forma, a fim de dar um sentido social às passagens. Ou melhor, investigar como a forma pode começar a ser percebida como espaço público significativo. Neste sentido, propomos um volta aos elementos-chave que constituem o significado original de "passagem".

As passagens servem, em certos casos, para superar obstáculos. Independente das mudanças nas grandes infraestruturas, estas pequenas intervenções no desenho urbano podem ter um impacto importante e dar resposta a problemas urgentes que não podem esperar por longos processos de planejamento e intervenções em grande escala. Apesar de o conceito de cidade contínua, sem ruptura, ser uma utopia dificilmente alcançável, ideias tais como micropassages e atalhos, podem dar respostas rápidas e eficazes para estas questões urbanas universais. Assim, o tema Passagens permite articular o cheio e o vazio, a velocidade e a lentidão, o móvel e o imóvel, o estético e o funcional, a alteridade e a segurança, e repensar a hierarquia das redes, particularmente o das redes primárias, hoje muito dominantes. Na esteira das leis de zoneamento, cabe perguntar se as passagens podem também ajudar a vincular a cidade, a unir os bairros mais ricos aos mais pobres, a periferia, ao centro, os sistemas de transporte de diferentes modos.

Ao integrar o tecido urbano fragmentado, as passagens permitem que seus habitantes cheguem a destinos que anteriormente eram inacessíveis a eles, e, assim, ajudá-los a se tornarem cidadãos, no sentido pleno da palavra. É em função disso que a implementação de tais "passagens" constitui um dos grandes desafios do nosso mundo urbano contemporâneo.

Para a boa movimentação e circulação do pedestre exije-se uma mínima condição no espaço público. Vles e Sylvie (2010) ressaltam que o espaço público (a praça, a rua, o espaço de encontro) convida à manifestação multicultural e à divisão do próprio espaço. Lynch (1960) ressalta que os limites, as fachadas dos imóveis e outros equipamentos contribuem de maneira fundamental para a qualidade dos 


\section{Revista Nacional de}

Gerenciamento de Cidades

espaços públicos, principalmente pela maneira que são projetados e executados. Caminhar é um ato espontâneo para todos que tenham condições físicas de exercer

Ascher (2010) debate o duplo compartilhamento da rua, indicando que esta deve ser um lugar capaz de agregar e de servir e não apenas de ligar lugares. Em sua argumentação, a rua da cidade contemporânea é distinta da rua da cidade moderna, pois na segunda as ruas são constituídas como os elementos de ligação dos espaços monofuncionais - ruas locais situadas em bairros residenciais, autoestradas que ligam áreas urbanas distintas ou ruas que ligam bairros comerciais, entre outras. Já na contemporaneidade, as ruas abrigam diversos tipos de atividades, adquirindo um caráter multifuncional.

No entanto, a maioria das ações e políticas de circulação e transporte não concede a devida atenção às ruas, principalmente às calçadas, infraestrutura fundamental para ampliar a mobilidade a pé, impondo condições de deslocamentos não condizentes com a qualidade merecida pelo cidadão que opta pela caminhada em suas viagens cotidianas (Malatesta, 2007). A rua é considerada parte fundamental do espaço público, que segundo Hetzberger (1999) é o território de cidadania e de civilidade.

Ou seja, justificar a existência das calçadas como somente espaços para ligação de um ponto a outro é possuir uma visão extremamente utilitária do seu uso, pois as calçadas, por serem locais públicos, são também um ponto de encontro para a socialização, lazer ou simplesmente para vermos e sermos vistos. Os espaços de permanência de forma pontual acontecem, na maior parte das vezes, em espaços pré-definidos para a realização de atividades de convívio e recreação. Esses locais costumam ter uma condição ambiental adequada para que haja apropriação por parte das pessoas. Já os espaços de permanência de forma linear se dão em espaços que são considerados de circulação e passagem, nos caminhos percorridos pelos pedestres, como por exemplo, as calçadas, os canteiros centrais que tenham amplitude. 


\section{Revista Nacional de}

Gerenciamento de Cidades

Os espaços de passagem podem ser percebidos em espaços prédeterminados para a realização de atividades de lazer e de convívio, mas, por alguma razão, tornam-se apenas de passagem e não do encontro. As calçadas e as ruas são espaços de passagem que fazem a circulação de forma linear e são nesses locais que os pedestres se deslocam para a realização de suas atividades. Porém, as calçadas, sobretudo na contemporaneidade não necessitam de ter uma só função, a de passagem, pois tem potencialidades para que o usuário permaneça. Os conceitos de passagem e permanência não são conceitos opostos, mas que podem se complementar.

Assim, o objetivo é revalorizar e dar sentido social a estes articuladores essenciais, que sempre estiveram presentes em nossas cidades, mas que, em muitos casos, estão em más condições e comprometem a qualidade da mobilidade dos pedestres.

Diante do entendimento das possibilidades de movimento do pedestre no espaço público, esta pesquisa analisa o cruzamento da Rua da Consolacão e Avenida Paulista, pois o espaço público nesta região possui papel fundamental na microacessiblidade aos modais de transporte e aos equipamentos e atividades existentes, um espaço de passagem e permanência.

\section{PROCESSO METODOLÓGICO}

Por meio da análise comportamental da observação direta, e do método desenvolvido Jan Ghel em seu livro How to study a public life (2003) e seus desdobramentos na publicação de mesma autoria intitulada Towards a Fine City for people - Public space and public life (2004), foram feitas adaptações para a análise da área de estudo.

Ghel busca-se indicar a situação crítica da atual circulação pedonal nesta região a partir da valorização de dois atos simultâneos: "passagem" e "permanência" 


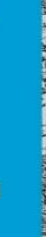

Revista Nacional de

Gerenciamento de Cidades

permanecer, destacando principalmente os conflitos que o pedestre encontra no espaço público.

\section{OBJETO: O MOVIMENTO DO PEDESTRE NO ESPAÇO PÚBLICO NA RUA DA CONSOLAÇÃO E AVENIDA PAULISTA}

O alcance do sistema de transportes que conecta a área de estudo possui caráter metropolitano e localiza-se no vetor sudoeste da cidade de São Paulo, onde há maior desenvolvimento quando se fala de infraestrutura urbana (Villaça, Zioni, 2005).

As duas linhas de metrô que ali se cruzam, a Linha 2 (verde) e a Linha 4 (amarela) se articulam ao sistema de trem metropolitano. A linha amarela conecta-se com três das cinco linhas de metrô em operação na metrópole, assim como com algumas linhas de trem. Essa área pode ser acessada pelo corredor de ônibus Campo-Limpo-Rebouças-Centro. A parada do corredor de ônibus na área de estudo localiza-se em frente ao término da Avenida Paulista.

A abrangência dessa área não é somente para serviços, mas também para lazer. Além disso, representa um pólo cultural, que agrega diversos equipamentos que atraem um público considerável aos fins de semana conforme

O uso do solo da região impacta diretamente na atração de usuário para um local, assim como os equipamentos urbanos. Existe uma significativa quantidade de comércio no térreo, edifícios residenciais com fachada ativa, prédios comerciais, uso misto, equipamentos culturais e institucionais. 
Revista Nacional de

Gerenciamento de Cidades

\section{ANÁLISE E RESULTADOS}

A estação Paulista - Linha 4 (Amarela), passa sobre a Rua da Consolação e tem seu embarque e desembarque na rua da Consolação. A estação Consolação, Linha 2 (verde) situa-se na Avenida Paulista. Há uma conexão subterrânea entre as estações ${ }^{3}$ que não é tratada nesse artigo.

Observa-se que, pela significância de ser uma centralidade modal, os sistemas de transportes públicos da área de estudo atraem diariamente inúmeros usuários que entram e saem de suas estações e paradas de ônibus.

Para melhor entendimento da área serão apresentadas duas situações para explicar o movimento dos pedestres no cruzamento e em seguida uma análise urbana.

\subsection{Rota 1: Desembarque do corredor de ônibus da Rua da Consolação em direção à Avenida Paulista.}

Foi em uma visita feita pela manhã, durante a semana, dia comercial, no mês de maio de 2015 , das 7:50 às 8:30 da manhã. $A$ autora colocou-se como observadora da área e conseguiu captar o movimento dos pedestres que, predominantemente, nessa situação, acontece quando desembarcam do corredor de ônibus que passa na Rua da Consolação e se direcionam à Avenida Paulista. A análise da situação 1 , a seguir, apresenta os seguintes pontos:

\footnotetext{
${ }^{3}$ Não foi permitido pela operadora Via Quatro a análise do comportamento dos pedestres/usuários na conexão entre as estações Paulista e Consolação do Metrô.
} 


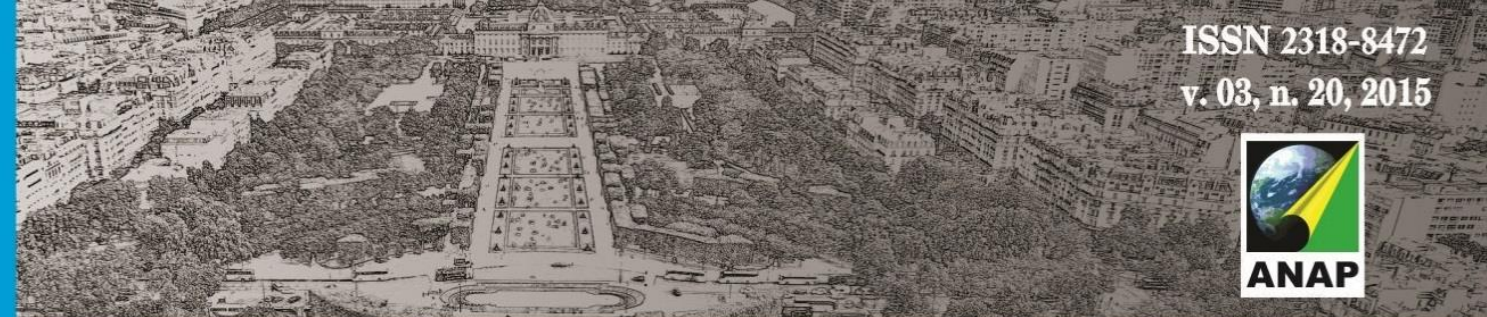

\section{Revista Nacional de}

Gerenciamento de Cidades

\subsection{Rota 2: Desembarque dos usuários oriundos do metrô Paulista (ambas} saídas na Rua da Consolação), ao mesmo tempo, uma quantidade significativa de pedestres que saem do corredor de ônibus em direção à Avenida Angélica.

Na segunda situação, a visita foi realizada em dia de semana, dia comercial, no mês de dezembro de 2014, das 7:30 às 8:30 da manhã. A situação leva a autora a observar alguns movimentos predominantes na figura abaixo:

Figura 4: Diagrama de rota 02

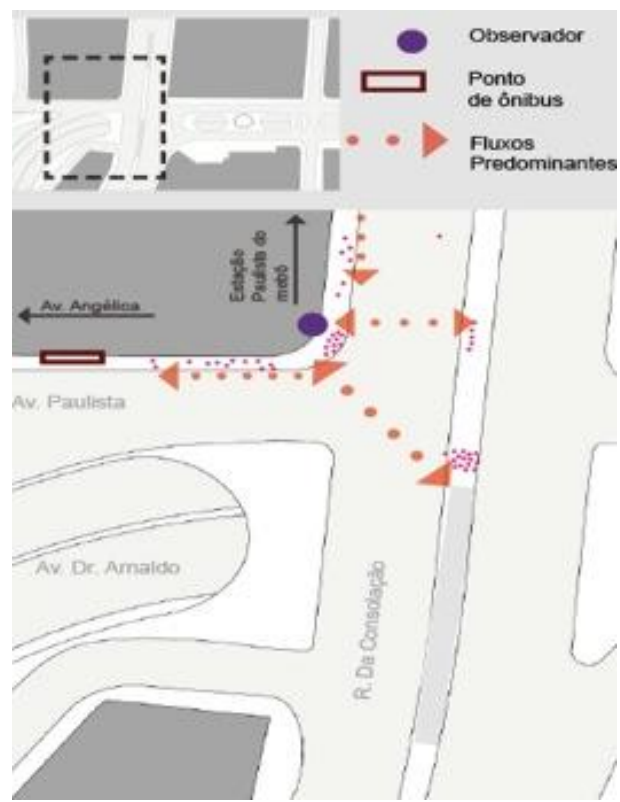

Fonte: Mapa Digital da cidade de São Paulo e Tratamento da autora

a) O espaço público em frente ao Bar Riviera não é utilizado, os pedestres se direcionam para a calçada que dá acesso à Avenida Angélica (figura 7a).

b) Os pedestres que desembarcam da estação Paulista do metrô acumulam-se na calçada em direção à Avenida Paulista e/ou ao corredor com conflitos entre os que 'aguardam' dos demais que circulam (figura $7 b$ )..

c) Acontece um cruzamento em " $x$ " quando o usuário desembarca da estação do corredor de ônibus em direção à Avenida Angélica (figura 8). 


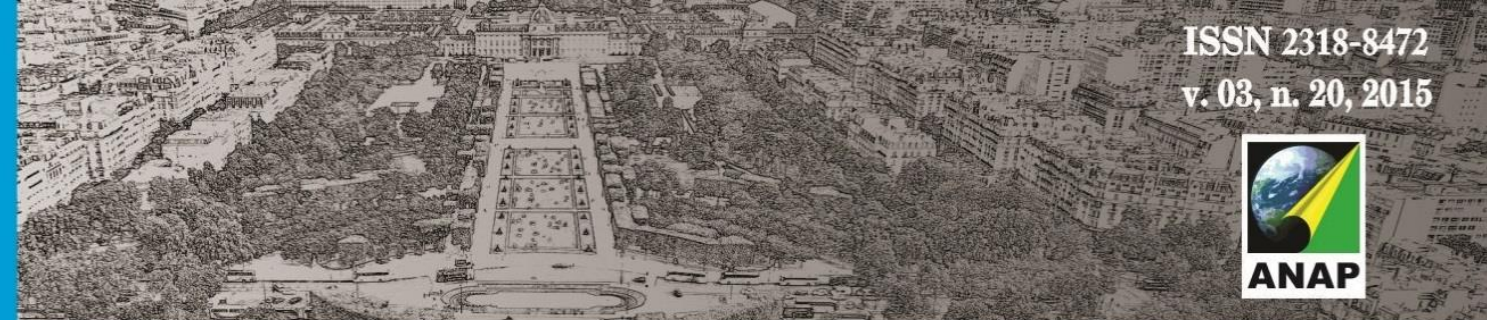

\section{Revista Nacional de}

Gerenciamento de Cidades

Figura 7: Barreiras do acesso do corredor de ônibus

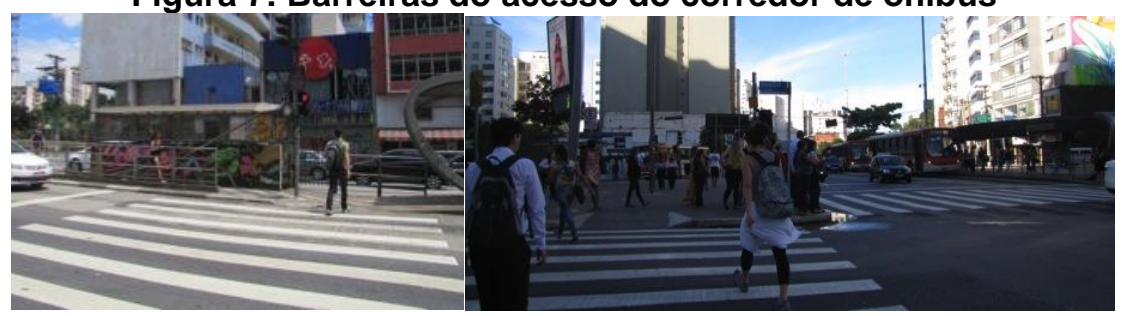

Fonte: Acervo da autora

Resultado: O corredor poderia ser tratado como uma potencialidade quando da sua implantação, mas o desenho urbano proposto faz dele uma fragilidade, reforçando as barrreiras pre-existentes.

Barreiras na calçada.

A Avenida Paulista tem o privilégio de ter uma padronização de calçadas pela iniciativa do poder público, porém seu entorno inclusive a Rua da Consolação, têm problemas de manutenção. Há presença de mobiliário urbano que torna-se barreira, como o posto móvel policial e a banca de jornal ao fundo.

Figura 8: Barreiras para movimento

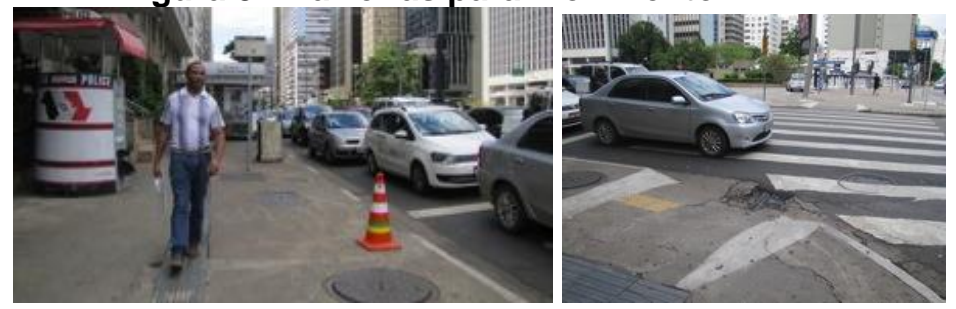

Fonte: Acervo da Autora

Resultados: Por isso, mesmo com abertura recente das estações de metrô da rua da Consolação, continua difícil a relação do pedestre com o espaço em que se movimenta. $O$ estado de conservação é péssimo inclusive as rampas entre a rua e calçadas.

Assim, mesmo que o movimento e a troca entre modais seja intenso no cruzamento em estudo, que o andar a pé é um sistema de transporte significativo na área, observa-se que a relacão entre as estações, a parada do onibus e o sistema viário é conflituosa e não há sinergia dos movimentos, bem como da repetição dos 


\section{Revista Nacional de}

Gerenciamento de Cidades

comportamentos do movimento dos pedestres que deveria ser melhor estudada no sentido da melhoria desse ambiente de passagem e de potencialidade de permanência.

\section{CONSIDERAÇÕES FINAIS}

Esse artigo partiu da premissa da realidade atual do cruzamento em análise que não há um desenho urbano que articule o sistema de transporte com o espaço público, um elo de ligação no percurso de diversos cidadãos numa passagem simbólica da cidade de São Paulo. A leitura da área escolhida indica os problemas gerais do movimento do pedestre no espaço público no entorno desses dois sistemas de transporte de massa, sendo eles o corredor de ônibus da Rua da Consolação e o cruzamento das Linhas 2 (verde) e 4 (amarela) do Metropolitano de São Paulo.

A maioria das dificuldades relacionadas ao movimento dos pedestres no meio urbano é causada pela grande prioridade dada aos veículos, pois a cidade moderna foi desenhada em função da fruição dos automóveis, esquecendo a sensibilidade do modal andar a pé, e por isso, não adaptou os espaços públicos para que o pedestre caminhe e permaneça com qualidade.

Nesse cruzamento, as transformações mais recentes, ocorridas principalmente com a chegada da linha Amarela do Metrô e com aumento do fluxo de pedestres, deflagram diversos conflitos que envolvem a ausência de desenho urbano e de políticas públicas em diversos níveis. Em resumo, deficiências de vários elementos que deveriam compor mais adequadamente o espaço público, atribuindo qualidade tanto para quem se movimenta, quanto para aqueles que poderiam "permanecer".

Essa análise reproduziu momentos diários da circulação dos pedestres, onde há diversos momentos de dificuldade para a sua movimentação. Os principais problemas encontrados foram: barreiras e obstáculos nas calçadas, além da má 
